\title{
Euzinho: o olhar das crianças e o registro de experiência acerca da selfie e do autorretrato
}

\author{
Euzinho: the children's look and the registry of experience about selfie \\ and self-portrait
}

\section{Euzinho: la visión de los niños y el registro de experiencia acerca de la selfie y del autorretrato}

Valdir Heitkoeter de Melo Junior'

https://orcid.org/0000-0002-3503-007X

Marsiel Pacífico²

https://orcid.org/0000-0002-2013-2073

Márcia Barbosa da Silva ${ }^{3}$

https://orcid.org/0000-0002-7635-963X

Resumo: Este artigo tem por objetivo apresentar os resultados alcançados no decorrer do desenvolvimento da oficina Euzinho, aplicada na Escola Municipal Professora Juventina Betim da Silva, em Telêmaco Borba/PR. As atividades realizadas são parte do cronograma estipulado pelo Projeto de Extensão LUME (Laboratório e Núcleo de Estudos de Mídia e Educação), inerente ao programa Universidade Sem Fronteiras. O tema da oficina foi alicerçado em dois motes: selfie e autorretrato. A partir de uma pesquisa exploratória de abordagem qualitativa, foram realizadas discussões temáticas oriundas de revisão bibliográfica, exposição de obras artísticas, desenvolvimento e aplicação de técnicas de retrato em pintura e, em registro fotográfico, buscou-se problematizar a utilização contemporânea midiática e reificada das selfies, oferecendo como contraponto a possibilidade de autorretratos potencializados de autonomia e expressividade artística, no intento de um processo emancipatório

I Mestrando em Cinema e Artes do Vídeo pela Universidade Estadual do Paraná (UNESPAR). Graduado em Licenciatura em Artes Visuais pela Universidade Estadual de Ponta Grossa (UEPG). E-mail: m.heitkoeter@gmail.com

${ }^{2}$ Doutor em Educação. Professor Permanente do Programa de Mestrado Profissional em Educação - PROFEDUC e Professor Adjunto da Universidade Estadual do Mato Grosso do Sul (UEMS). E-mail: marsiellp@gmail.com

${ }^{3}$ Doutora em Educação. professora adjunta do Departamento de Pedagogia da Universidade Estadual de Ponta Grossa. E-mail: marciauepg@gmail.com

Olhar de professor, Ponta Grossa, v. 24, p. I-I7, e-I5089.002, 202 I.

Disponível em https://revistas2.uepg.br/index.php/olhardeprofessor 
e de questionamento crítico do uso das mídias na atualidade, sobretudo para o público considerado jovem ou infantil.

Palavras-chave: Autorretrato. Selfie. Mídia. Literacia midiática

\begin{abstract}
This article has the purpose of presenting the achieve results throughout the development of the workshop Euzinho, applied at the Professora Juventina Betim da Silva Elementary School, in Telêmaco Borba/PR. The activities performed are part of the schedule stipulated by the Extension Project LUME (Laboratory and Nucleos of Study of Media and Education), inherent to the program University Without Border. The theme of the workshop was grounded in two mots: selfie and self-portrait. Based on an exploratory research of qualitative approach, theme discussions were performed based on review of literature, exposition of art work, development and application of portrait techniques in paintings and, in photograph registries, aimed at problematizing the contemporary media use and reinforced by selfies, offering as counterpart the possibilities of self-portraits powered by autonomy and art expressiveness, with the purpose of an emancipation process and of critical questioning of the use of media nowadays, mostly for the considered young or children's public.
\end{abstract}

Keywords: Self-portrait. Selfie. Media. Media literacy.

Resumen: Este artículo tiene por objetivo presentar los resultados alcanzados en el transcurso del desarrollo del taller "Euzinho", aplicada en la Escuela Municipal "Professora Juventina Betim da Silva, Telêmaco Borba/PR". Las actividades realizadas son parte del cronograma estipulado por el Proyecto de Extensión LUME (Laboratório e Núcleo de Estudos de Mídia e Educação), referente al programa "Universidade sem Fronteiras". El tema del taller se basó en dos asuntos: selfie y autorretrato. A partir de una investigación exploratoria con enfoque cualitativo, fueron realizadas discusiones temáticas procedentes de revisión bibliográfica, exposición de obras artísticas, desarrollo y aplicación de técnicas de retrato en pintura y, en registro fotográfico, se buscó problematizar la utilización contemporánea mediática y materializada de las selfies, ofreciendo como contrapunto la posibilidad de autorretratos potencializados de autonomía y de expresividad artística, en un intento de un proceso emancipatorio y de cuestionamiento crítico sobre el uso de los medios de comunicación en la actualidad, sobre todo para el público considerado joven o infantil.

Palabras-clave: Autorretrato. Selfie. Mídia. Educomunicación.

\title{
Introdução
}

A conceituação feita por Debord (1997), de um tempo moderno no qual o espetáculo se impõe como tônica social, apresenta uma sociedade do espetáculo na qual, em seu atual estágio, a vida está cada vez mais mediada pela imagem. Sobretudo no contexto digital, nosso cotidiano, sentimentos e ideias são compartilhados, essencialmente, de forma imagética, para um espaço público de mútua visualização entre os sujeitos. Nesse contexto, o sentimento da não visualização está inevitavelmente associado à sensação da não existência: não ser percebido configura uma forma ontológica moderna de não ser, porquanto tudo que é ocupa o palco do espetáculo. A força dessa lógica, costumeiramente, transcende a própria dimensão do campo virtual. Aquele que, por exemplo, opta por não estar nas redes sociais enfrenta um sentimento de estranheza e de não pertencimento, na força do imperativo metafísico que nasce com a fotografia: "poder tornar-se imagem significa talvez se tornar imagem e, mais cedo ou mais tarde, ter de tornar imagem" (TÜRCKE, 20I0, p. I82).

À medida que a coerção subjetiva se impõe, gradativamente com mais força, aqueles que estão à margem procuram, em geral, combater tal força de maneira reificada: adentram ao jogo do espetáculo. 
Em um contexto no qual as potências subjetivas impelem para a deterioração das potências individuais e formativas da linguagem, as formas de salvação ante o abandono daquele que não é visto no palco virtual também são meios de autonegação e de adesão ao imperativo linguístico do espetáculo de si (PACÍFICO, 20I7); o preço para salvar-se é, em grande medida, perder-se:

Ser é ser percebido. Mas ser percebido é ser tomado. E é preciso ser tomado tanto pelo mercado como pela retina artificial. Mas ambos, tanto o ser tomado economicamente quanto $\circ$ fotograficamente, trazem em si tanto $\circ$ significado criminalístico do provar, certificar indícios, registrar, controlar, como também o caritativo de tomar, abrigar, salvar. Eles reúnem em si o que a teologia nunca pode reunir em Deus sem contradição: tanto o olhar implacavelmente julgador sobre o mundo quanto o misericordioso (TÜRCKE, 2010, p. 189).

Se são incessantes os incontáveis atos virtuais que corroboram a leitura deste contexto, alguns fenômenos são indicativos do refluxo do movimento de deterioração do eu promovido pelo espetáculo de si. A compulsão por emitir e ser percebido por vezes ganha formas que tentam constituir, ainda que de maneira imagética, a identidade do sujeito. A prática fotográfica da selfie se apresenta como forma de compulsão à emissão que imprime uma identidade específica; a assinatura fotográfica daquele que emite é um estratagema para não perder a individualidade em meio à enxurrada de imagens que brotam a cada instante nas redes sociais. Se, em sua concepção, as redes sociais almejavam tornar-se ferramentas para potencializar a relação entre indivíduos, em seu uso contemporâneo elas se caracterizam como uma grande arena de disputa por atenção, reconhecimento e, por fim, pela própria existência. Dessa maneira, na selfie, a relação entre os sujeitos é mediada pela autentificação e identificação que o fotografar a si mesmo imprime. Nesses termos, a reificação da linguagem ganha força e suas estruturas se coisificam na mimesis entre homem e produto. A finalidade da linguagem abandona seu devir formativo para produzir atenção, para marcar. Assim, a selfie também pode ser compreendida como uma forma pessoal de estabelecimento de vínculo entre o emissor e o consumidor do espetáculo, o mesmo problema que a economia de mercado resolveu com a instituição da marca:

\footnotetext{
Um produto físico se torna uma marca quando é acrescido de algo mais - imagens, símbolos, percepções, sentimentos - para produzir uma ideia total maior que a soma de suas partes. Uma marca pode consistir em um único produto ou ser composta de vários que se espalham por muitas categorias. Mas no centro existe uma alma, uma identidade distintiva que toca no fundo dos consumidores e transcende a representação física em termos de forma do produto. (...) Do ponto de vista do marqueteiro, a marca é uma promessa, um pacto. Da perspectiva do consumidor, é uma série de associações, percepções e expectativas que existem em sua cabeça. As associações de marca são criadas, mantidas e incrementadas por toda experiência e encontro que o consumidor tem com ela (BATEY, 2010, p. 27-28).
}

Tal contexto denota que o uso das selfies em seu sentido comum coisifica os sujeitos e expropria da arte suas possibilidades emancipatórias. Visto que tal prática é cada vez mais comum entre o público

Olhar de professor, Ponta Grossa, v. 24, p. I-19, e-I5089.002, 2021.

Disponível em https://revistas2.uepg.br/index.php/olhardeprofessor 
infantil, buscamos, a partir dos estudos teóricos críticos sobre mídia e modernidade desenvolvidos no Laboratório e Núcleo de Estudos de Mídia e Educação (LUME) ${ }^{4}$ da Universidade Estadual de Ponta Grossa (UEPG), desenvolver um Projeto de Extensão que propiciasse novas significações entre a criança e seu autorretrato em sua forma midiática mais comum: a selfie. Esse projeto se inscreve no âmbito de uma pesquisa maior desenvolvida pelo LUME sobre a relação das crianças com a mídia. Trata-se de uma pesquisa de tipo exploratória (GIL, 2007), realizada numa abordagem qualitativa que se fundamenta na interpretação e na compreensão do cotidiano (SAMPIERI, COLLADO, LUCIO, 20I3, YIN, 20I6). Segundo Bogdan e Biklen (1994, p.5I) "o processo de condução de investigação qualitativa reflete uma espécie de diálogo entre os investigadores e os respectivos sujeitos, dado estes não serem abordados por aqueles de uma forma neutra". No diálogo com as crianças acerca da sua relação com a mídia, chamou a atenção a utilização majoritária para a produção de selfies, o que gerou o mote da experiência relatada neste artigo.

Autores como Debord, Türcke, Batey, Cohn, juntamente com outros já citados, compuseram nossos estudos e fundamentaram a dimensão crítica formativa do projeto. De maneira propositiva, foram apresentadas obras de artes de diferentes escolas, relacionadas a metodologias ativas que envolveram rodas de conversa, pintura e registros fotográficos. $O$ conjunto dessas atividades resultou no projeto batizado de Euzinho.

As atividades propostas foram desenvolvidas na Escola Municipal Professora Juventina Betim da Silva, em Telêmaco Borba/PR. A escola se localiza no bairro São João, na periferia da cidade. Parte inerente ao Projeto de Extensão, esse deslocamento visa contribuir com o cotidiano escolar de cidades com baixo IDHM (Índice de Desenvolvimento Humano Municipal). Apesar de o município ter registrado um IDHM de $\mathbf{0 , 7 3 4}$, considerado alto, conforme dados do último censo realizado pelo Instituto Brasileiro de Geografa e Estatística, em 2010, a cidade apresenta níveis relevantes de desigualdade e falta de acesso a direitos essenciais, como saneamento básico, em bairros periféricos. As atividades da oficina previam aproximação e diálogo com as crianças do terceiro ano do Ensino Fundamental, que conta com 26 alunos.

A escolha do tema, as etapas da oficina e os resultados alcançados compõem parte deste trabalho. Expressa-se o intuito de compartilhar algumas impressões a partir dessas vivências, bem como avaliar os resultados por um viés artístico e pedagógico, numa tentativa de sugerir a instauração de algo novo a partir de reflexões acerca do uso das mídias, da noção do ser humano como indivíduo a partir do autorretrato e da expressão artística por meio da criação (desenho, pintura e escrita).

\footnotetext{
${ }^{4}$ Ressalta-se que os projetos realizados pelo Programa LUME têm a aprovação do Comitê de Ética na Pesquisa e, para a realização desta proposta houve autorização dos responsáveis pelos jovens.
} 
Valdir Heitokoeter de Melo Junior, Marsiel Pacífico e Márcia Barbosa da Silva

As seções priorizam uma narrativa temporal dada a natureza do texto como relato de experiência. Elas se organizam em: "Autorretrato e selfie, primeiro dia", "Por que as pessoas tiram selfie? Porque é pra colocar na identidade, segundo dia" e "Que tinta eu tenho que usar pra fazer cor de pele, professor? Terceiro dia". No primeiro dia, buscou-se discutir a utilização das selfies no cotidiano, deslocando tal prática de uma lógica de reprodução estética para um fazer artístico, historicamente alicerçado no conceito de autorretrato. No segundo dia, discutiu-se as compreensões que os alunos apresentavam sobre a função social da selfie e propiciou-se uma experiência estética com a fotografia, a qual permitisse uma prática singular e afetiva de autorrepresentação. No terceiro dia, descreve-se a experiência estética de retratar o outro e as derivações formativas que tal prática suscita. Destaca-se a busca pela fidelidade das formas e pela fuga das generalizações grosseiras. Por fim, nas considerações finais, denominadas "Olhar para si fora do espelho, o duplo", apresenta-se o repertório que tais atividades propiciaram, no reencontro da representação estética de si e do outro, e como tais formas podem produzir sentidos singulares por meio da experiência estética. Destaca-se também a relevância de uma prática pedagógica para as mídias, a qual concilie o contexto tecnológico do mundo moderno com as práticas emancipatórias.

\section{Autorretrato e selfie, primeiro dia}

No primeiro dos encontros matutinos, os relatos, as primeiras frases e os primeiros traços para aprender com os pequenos um pouco mais sobre a figura de si mesmo. De dentro para fora, o corpo como limite para o resto do mundo, a representação de si pelos olhos dos alunos em três encontros, três dias consecutivos. Abaixo, estão descritas as experiências, alguns detalhes, espantos e descobertas junto aos alunos durante as oficinas.

A escolha do tema para a oficina é parte das inquietações pertinentes ao grupo do Projeto de Extensão LUME. Durante discussões em grupo, evidenciou-se a preocupação em abordar temas contemporâneos. Portanto, pesquisas e esforços para, constantemente, reavaliar nossa condição e os reflexos a que estamos sujeitos ao utilizarmos as mídias, tornaram-se motivo de especial atenção. Assim, após dialogarmos a respeito da relação dos alunos com as mídias, a equipe chegou a uma proposta de oficina, tendo em vista uma abordagem que permitisse verificar o grau de interesse e conhecimento que os alunos participantes tinham a respeito do uso de smartphones para se autorretratar/tirar selfie.

O autorretrato é a representação que o ser humano faz de si mesmo, colocando-se como figura central de um registro. De acordo com Pessoa (2006, p. I), “o autorretrato é, de certa forma, uma afirmação de presença, ou melhor, um registro dela". O autorretrato é um gênero recorrente na história

Olhar de professor, Ponta Grossa, v. 24, p. I-19, e-I5089.002, 202 I.

Disponível em https://revistas2.uepg.br/index.php/olhardeprofessor 
da arte e tem Albert Dürer, no Renascimento, como o primeiro artista a realizar uma série de autorretratos, que teve início entre os anos 1493 e 1500.

O termo selfie não tem uma origem precisa, há controvérsias sobre sua origem, mas sugere-se que pode tratar-se de uma variação da palavra self-portrait (autorretrato) ou, ainda, um neologismo a partir da palavra self (em inglês, "eu" ou "a própria pessoa") e o sufixo ie (em inglês "inho(a)"), resultando em uma palavra como "euzinho":

\begin{abstract}
O indivíduo contemporâneo faz seu autorretrato/selfie, posta no ethos midiatizado para ter vida no bios virtual, locais novos criados pelo homem moderno e suas tecnologias, que fazem parte do cotidiano deste tempo, e do qual se pode dizer, parafraseando Vinícius de Moraes no que tange à imagem/selfie postada na rede, "Que seja imortal posto que é chama. Que seja infinito enquanto dure", mesmo que apenas por alguns segundos até ser substituída pela nova fotografia. (COHN, 2015, p. 8).
\end{abstract}

Autorretrato e selfie ocupam uma posição semelhante, considerando-se que ambos são meios para a autorrepresentação dos sujeitos. Para Cohn (2015), o barateamento das tecnologias de reprodução de imagens foi um dos fatores essenciais para que a representação de si mesmo passasse a ser um fenômeno da cultura atual. "O selfie é uma prática atual, um comportamento que permeia todas as camadas da sociedade. As pessoas fazem selfie de cenas de seu cotidiano, sozinhas ou com outras pessoas" (COHN, 20I5, p. 6).

Apresentar o que são autorretratos e o que são selfies, mencionar a distinção diacrônica que marca a separação dos termos supramencionados, foi a primeira etapa da oficina, considerando-se que o autorretrato está mais vinculado à ideia de pintura ou escultura como linguagem artística e a selfie é um termo contemporâneo estritamente ligado à fotografia. O recurso utilizado para apresentar esses dois conceitos aos alunos, num primeiro momento de diálogo, foram imagens de autorretratos de artistas como Albert Dürer, Pablo Picasso, Frida Kahlo, Rembrandt, entre outros.

Nesse primeiro momento, pôde-se notar que os alunos não tinham nenhuma familiaridade com esses nomes, portanto não conheciam essas obras de arte. Por outro lado, quando perguntados a respeito das selfies, muitos deles mencionaram experiências pessoais que envolviam parentes próximos, como os pais ou irmãos, e, inclusive, eles mesmos.

A segunda etapa da oficina era estender o diálogo a um nível no qual os alunos pudessem reavaliar o que entendiam sobre o tema e expressar suas ideias de maneira mais demorada. $O$ intuito desse diálogo era verificar de que maneira a apresentação de obras de arte e imagens relacionadas ao tema poderiam influenciar o discurso dos alunos.

Figura I: Reunião com alunos e bolsistas do LUME para discutirmos autorretrato, 2017. 


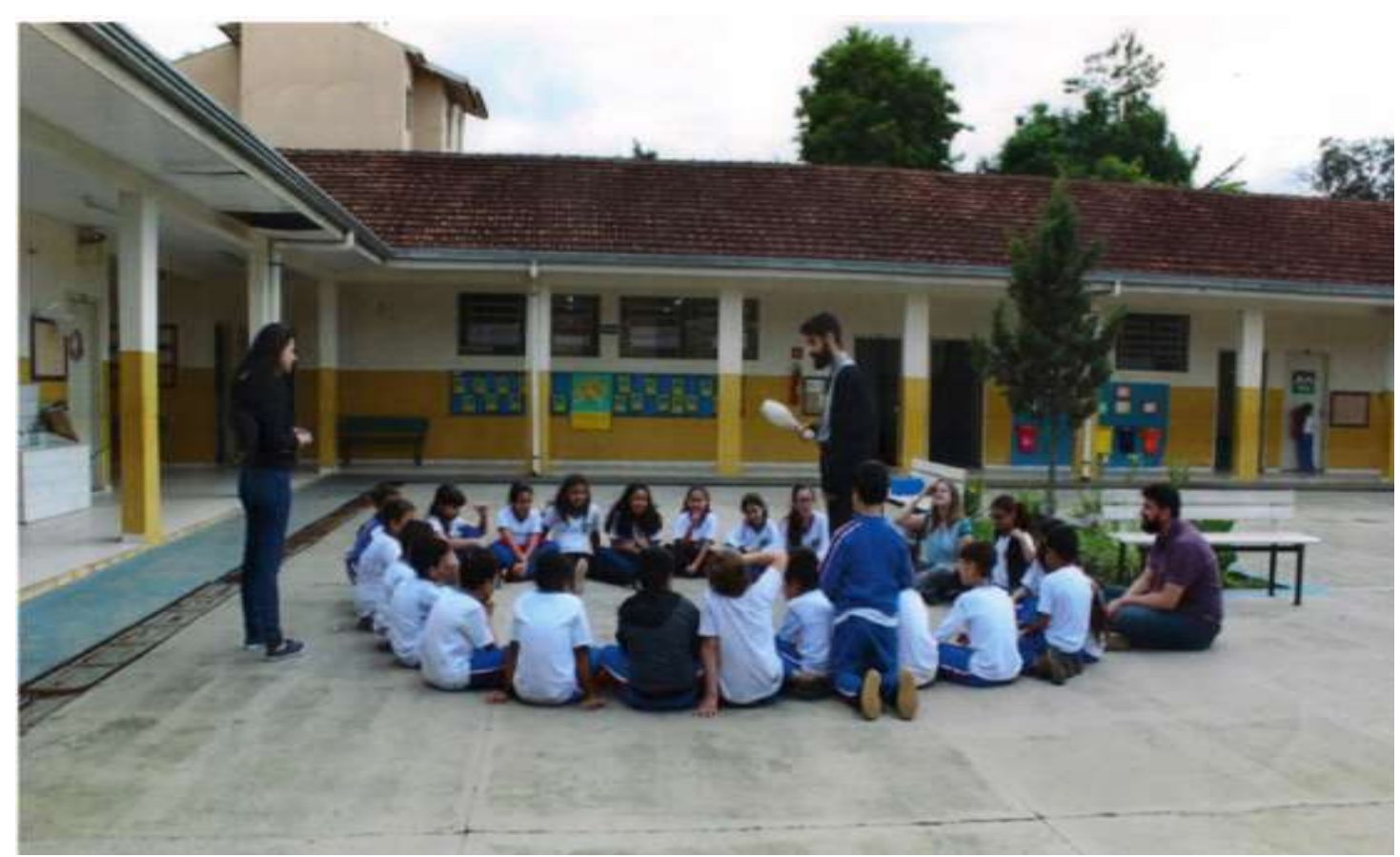

Fonte: autores, 2017

\section{"Por que as pessoas tiram selfie? Porque é pra colocar na identidade", o segundo dia}

Na segunda manhã na Escola Municipal Professora Juventina Betim da Silva, deu-se continuidade ao diálogo junto às crianças. A proposta feita aos alunos, num primeiro momento, pedia que eles escrevessem uma frase a respeito do que fora conversado no dia anterior. $O$ estímulo dado aos alunos, além da memória do dia anterior, adveio de questionamentos, como "O que são selfies?", "Por que as pessoas tiram selfie?" ou "O que aprendemos ontem sobre selfies e o que vocês sabem sobre isso?".

Os alunos responderam utilizando um pequeno papel, o qual foi recolhido e digitalizado. Abaixo, e respeitando a forma em que escreveram, aparecem transcritas algumas respostas que os alunos deram:

\footnotetext{
"Porque é para colocar na identidade" (aluna E.)

"Porque eles tiram para colocar em foto do perfil do watespp e feisiboquk" (aluna M. V.)

"A selfie serve para gente tirar em todo lugar no celular" (aluno J. G.)

"As pessoas tiro selfe ficar para um rilique" (aluna A. G.)

"As pesoas para min tiram selfie porque eles querem mostrar para os amigos verem" (aluno N.)

"Tiram foto para postar nas redes sociais" (aluna A.)

"Para quoando elas ficarem velhinhas elas verem as fotos delas" (aluno S. V.)

"A minha mãe e meu pai tira selfie para mandar para Feisebuk e wpisap" (aluna S.)
}

A frase da aluna E. menciona o uso da selfie para "colocar na identidade". É possível que a interpretação da aluna do que venha a ser "selfie" esteja atrelada à fotografia de si para uso no documento de identidade. Uma associação que coloca o sujeito como figura central e, pode-se sugerir, Olhar de professor, Ponta Grossa, v. 24, p. I-19, e-I5089.002, 2021. 
está conectada a uma memória da aluna. Pode-se supor que a foto em tamanho $3 \times 4$ guarde semelhanças formais com os enquadramentos usuais de quem fotografa a si mesmo utilizando-se da postura "selfie". A fala da aluna, além disso, dá margem para tatear outros campos de interpretação e analogias.

Identidade, de acordo com o dicionário, para além de um documento de identificação, é um substantivo feminino o qual agrega um conjunto de características que tornam possível verificar singularidade e transformar sujeitos em "indivíduos". Ainda de acordo com o dicionário (BUENO, 2000, p. 346), um indivíduo é um substantivo masculino que indica "qualquer corpo ou ser que constitui um todo distinto em relação à espécie a que pertence”. Logo, reiterando, a identidade é uma das possíveis definições da distinção entre sujeitos, pessoas etc.

[...] identifica três estágios do desenvolvimento da imagem corporal na infância, quais sejam: (a) "experiências precoces do corpo, que correspondem aos primeiros meses de vida do bebê, quando a percepção de corpo da criança (afetos, movimentos e sensações) baseia-se na sua relação com a mãe"; (b) "consciência inicial da imagem corporal com integração de experiências internas e externas", que se estende até a fase na qual a criança começa a andar e diferenciar o eu e o mundo externo e (c) "definição e coesão do eu corporal como base da consciência do eu", que começa a partir dos I5-18 meses, quando a autonomia e a consciência do próprio eu emergem e sinalizam o senso de identidade corporal (SOUSA, et al., 20l4, p. 49).

Pode-se destacar a aluna M. V. e a aluna A., as quais, ainda que não façam uso pessoal e cotidiano dessas ferramentas, têm conhecimento acerca do que possam ser as plataformas WhatsApp e Facebook e salientam que o registro das selfies se dá em razão de uma finalidade.

O aluno J. G. indica que a ideia de mobilidade e acessibilidade por meio do celular é o que garante a prática da selfie.

Já os alunos A. G. e S. V. permitem sugerir a compreensão de que a fotografia selfie é a garantia de uma relíquia pessoal e um atributo da memória por meio do registro da imagem.

$\mathrm{O}$ aluno N. traz a ideia inerente à selfie como indicador de sociabilidade e criação de vínculo.

Por fim, a aluna S., para além da compreensão de M. V. e A., reconhece a presença das selfies no exemplo vivenciado no cotidiano familiar.

Essas são algumas interpretações breves que podemos considerar como parte do resultado das atividades elaboradas. No entanto, reconhece-se que cada frase supracitada poderia resultar em uma interpretação mais aprofundada e revelar, na particularidade de cada aluno, uma percepção valiosa para se discutir a relação dos alunos/crianças com as mídias e a figura de si mesmos no mundo. Assim, a relação individual do sujeito com as imagens é uma construção natural:

Nessa história, assim como em outra do mesmo gênero, a identidade constrói-se pulsionalmente no quadro de um estranhamento subjetivo, interno, mas, principalmente, a partir de imagens externas que circulam na sociedade mediatizada 
em todas as formas industriais possíveis. A identidade viabiliza-se como um jogo de signos realizados por imagens, que circulam aceleradamente, de forma contagiante, à maneira de um processo viral. Não são imagens com uma sombra referencial na realidade, capazes de suscitar a reflexão, mas simulacros que se incorporam aos sujeitos, criando um outro tipo de relação com o mundo físico (SODRÉ, 20I0, p. 174).

Se, por um lado, essas imagens não são uma sombra referencial direta da realidade, capaz de suscitar reflexão, por outro lado, elas constituem um caminho para alcançar esse estágio. Participar, por meio do diálogo, do cotidiano do aluno e suas compreensões, trazidas de além das margens do cotidiano escolar, é um dos possíveis caminhos para compreender suas perspectivas acerca da mídia. Para Silva, em investigação do espaço ocupado pelas mídias e suas possibilidades emancipatórias, é necessário questionar as ausências, o não óbvio, para se aproximar das condições que precedem e servem de caminho para a emancipação do indivíduo:

Requer ainda um questionamento das ausências que exige um "esforço de imaginação" para pensar sobre as opções não tomadas, ou ainda para revelar caminhos encobertos, abandonados, esquecidos, insuspeitados. Além disso, é preciso também apontar para as emergências, para aquilo que surge apesar das condições adversas em contextos não considerados como prioritários, é aquilo que surge às margens, nas fronteiras, nas conversas cotidianas "esquecidas no baú de espantos” (SILVA, 20I I, p. 53).

Investigar tais ausências, os caminhos menos óbvios, possibilita o acesso, tanto do professor como do aluno, a um degrau importante rumo à emancipação. Portanto, o autorretrato, assim como a selfie, incorporam temas que possibilitam trabalhar a investigação dos sujeitos e da compreensão de si em face do mundo utilizando-se dessas ausências, transformando-as em presença, em tema a ser discutido, em caminho para aprendizagem e para reavaliações sobre o cotidiano:

A emancipação é uma construção histórica, não somente em relação à história do conceito, às diferentes significações que lhe são atribuídas, como também em relação a uma trajetória dentro da história do sujeito, daí seu caráter plural. São emancipações em relação ao grau de sujeição ou de autonomia frente aos diversos desafios sociais, espirituais e afetivos que abrangem a compreensão da condição humana (SILVA, 20I I, p. 54).

Como já mencionado, a selfie, ou o autorretrato, possibilitou verificar diversos níveis de interpretação dos alunos a respeito do tema. Os registros escritos, por exemplo, permitiram apreciar o grau de compreensão/consciência dos alunos a partir do raciocínio e registro aos quais já estão familiarizados. A etapa que sucedeu à escrita foi o registro das selfies.

A proposta consistia nas seguintes etapas: a equipe do Projeto solicitou à direção e coordenação da Escola que fosse elaborado um documento de requerimento de permissão do uso da imagem das crianças. Esse documento foi enviado para suas casas e assinado pelos pais ou responsáveis. Dos 26 alunos, 17 puderam participar dessa etapa da atividade, sendo concedido o uso da imagem por meio das assinaturas.

Olhar de professor, Ponta Grossa, v. 24, p. I-19, e-I5089.002, 2021.

Disponível em https://revistas2.uepg.br/index.php/olhardeprofessor 
Solicitou-se aos alunos que levassem para a escola um brinquedo ou objeto do qual gostassem ou com o qual se identificassem, além de uma roupa que fosse de sua preferência. Esse pedido visava à singularidade, às particularidades de cada aluno, pois, como supramencionado, o indivíduo se caracteriza como um corpo ou ser distinto dos demais, portanto o uniforme utilizado pelos alunos poderia anulálos ou distanciá-los de suas particularidades. $O$ intuito desse pedido foi, justamente, que os alunos manifestassem suas preferências estéticas e afetivas por meio de objetos ou da escolha de uma roupa.

As selfies foram registradas dentro das dependências da Escola e os alunos tiveram a liberdade de escolher o espaço com que mais se identificassem. Utilizou-se uma câmera semiprofissional modelo Canon EOS - T5i e um tripé de suporte. Foi realizada também uma demonstração dos mecanismos básicos de funcionamento da câmera e alguns dos seus recursos, como temporizador e zoom. Os alunos escolhiam, então, o local, acionavam o temporizador, posicionavam-se e aguardavam que o registro fotográfico fosse concluído. Como forma de proteger as identidades, os rostos das crianças foram substituídos pelos rostos desenvolvidos na oficina de pintura, realizada no dia seguinte.

Figura 2: Selfie realizada pelo aluno R.

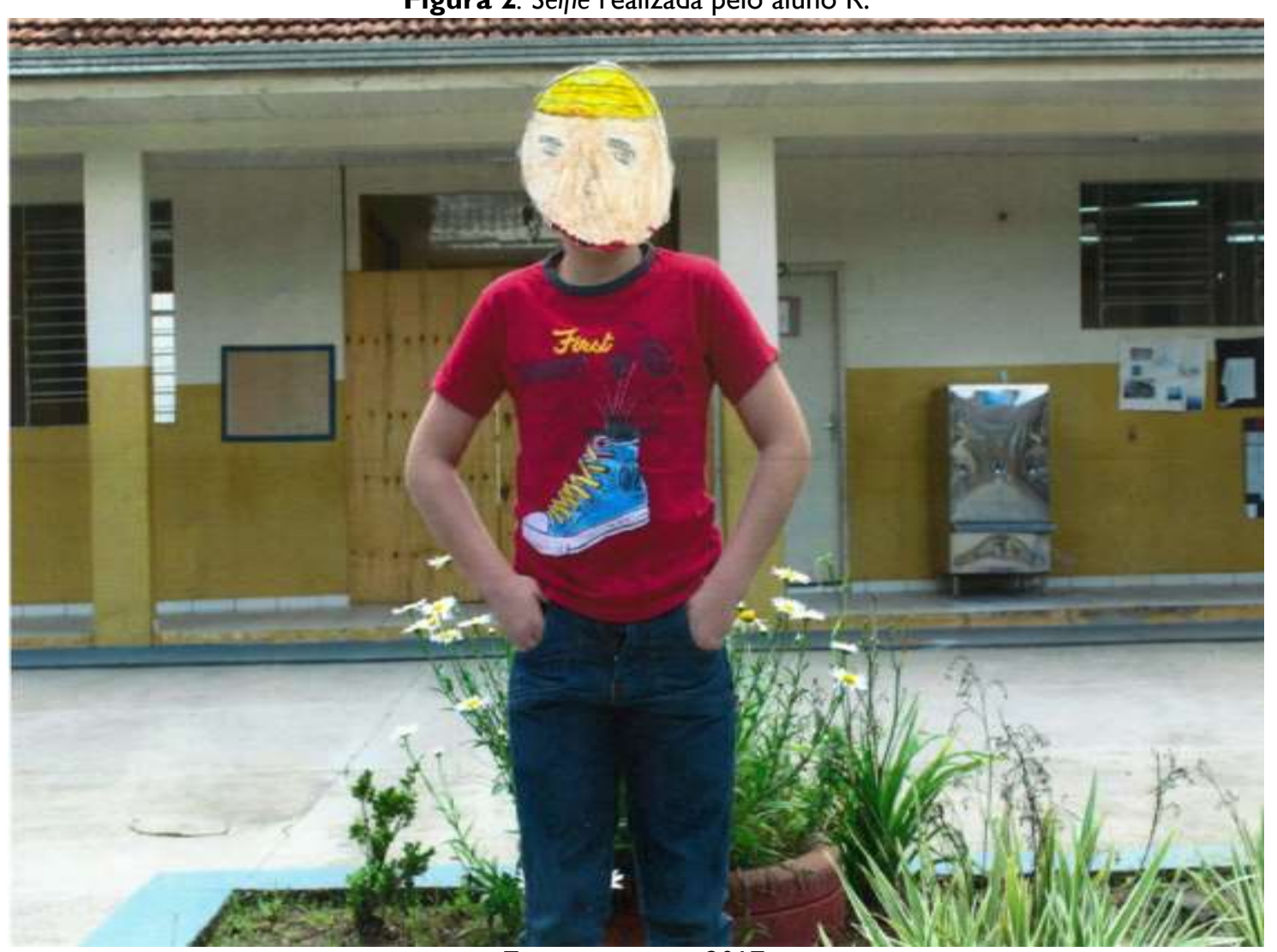

Fonte: autores, 2017.

Olhar de professor, Ponta Grossa, v. 24, p. I-I7, e-I5089.002, 202I.

Disponível em https://revistas2.uepg.br/index.php/olhardeprofessor 
Figura 3: Selfie realizada pelo aluno J. G.

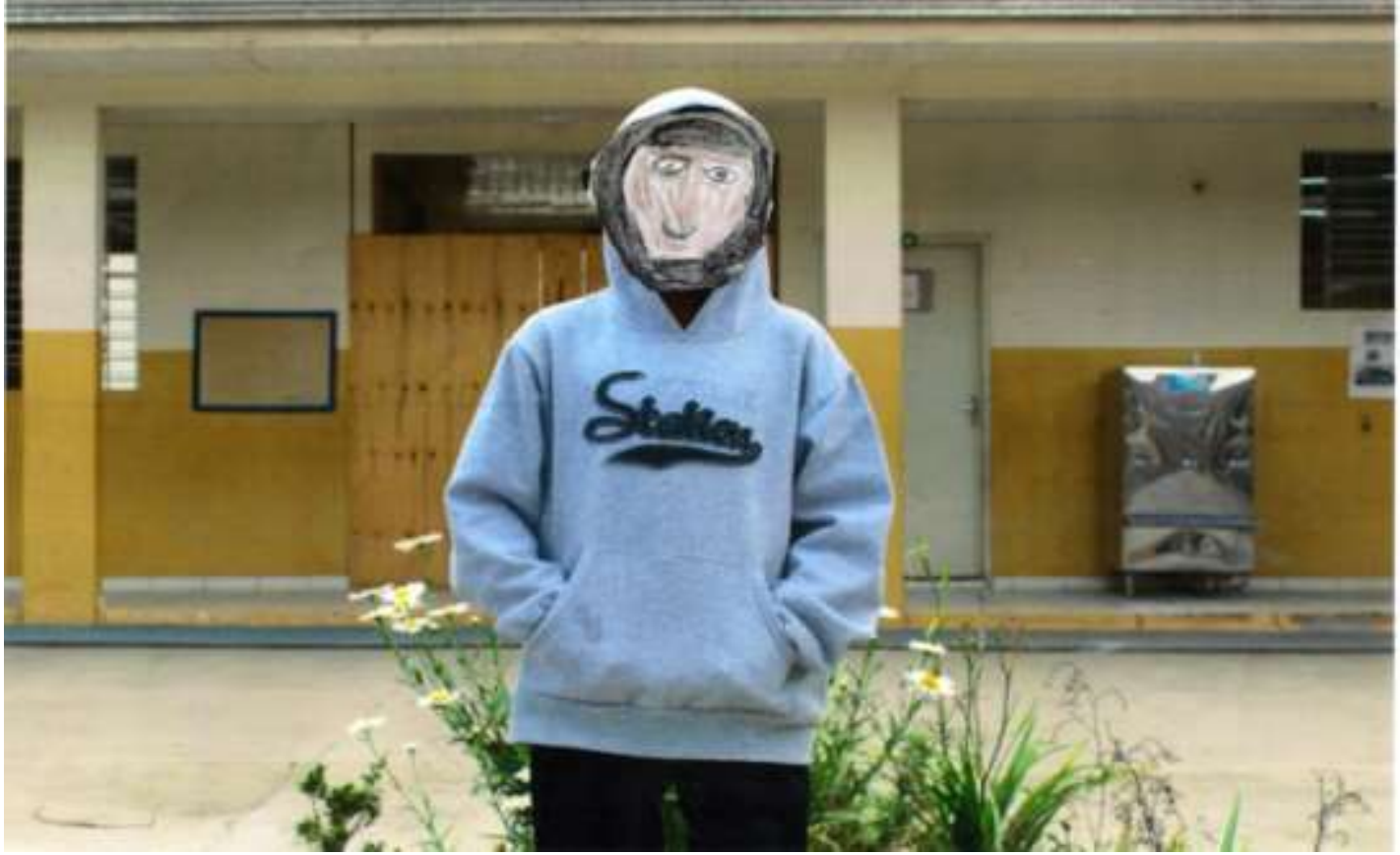

Fonte: autores, 2017.

Figura 4: Selfie realizada pelo aluno $\mathrm{N}$.

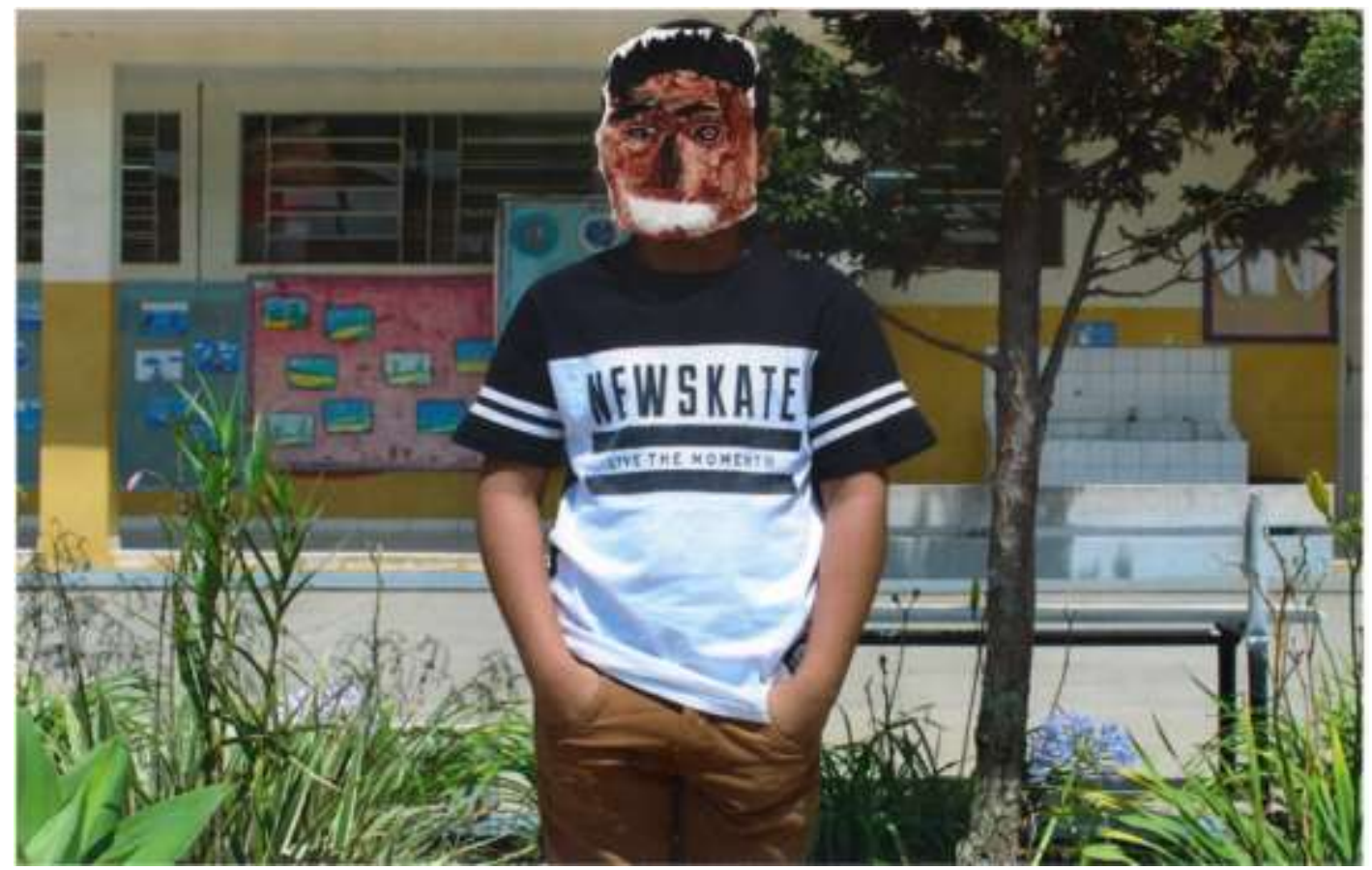

Fonte: autores, 2017.

Olhar de professor, Ponta Grossa, v. 24, p. I-19, e-I5089.002, 202 I.

Disponível em https://revistas2.uepg.br/index.php/olhardeprofessor 
“Que tinta eu tenho que usar pra fazer cor de pele, professor?", o terceiro dia

A terceira manhã de atividades foi também o ato final da proposta da oficina e, para este dia, predeterminou-se a produção de pinturas à maneira de autorretratos. As atividades tiveram início com uma mostra, por meio de apresentação de slides, das fotografias que os próprios alunos haviam feito no dia anterior. Essa etapa de preparação tinha dois objetivos: o primeiro, e principal objetivo, era que os alunos vissem suas selfies por trinta segundos, no máximo, e memorizassem as cores e formas da fotografia para, posteriormente, produzirem seus autorretratos. O segundo, era propiciar àqueles alunos que não puderam ser fotografados devido à não autorização dos pais, a oportunidade de ver as fotografias dos colegas e produzir uma pintura de observação.

A memorização da fotografia e a conseguinte produção de uma pintura tinham por objetivo estimular a criatividade e a capacidade de memorização dos alunos.

Figura 5: Conjunto de autorretratos pintados pelos alunos.

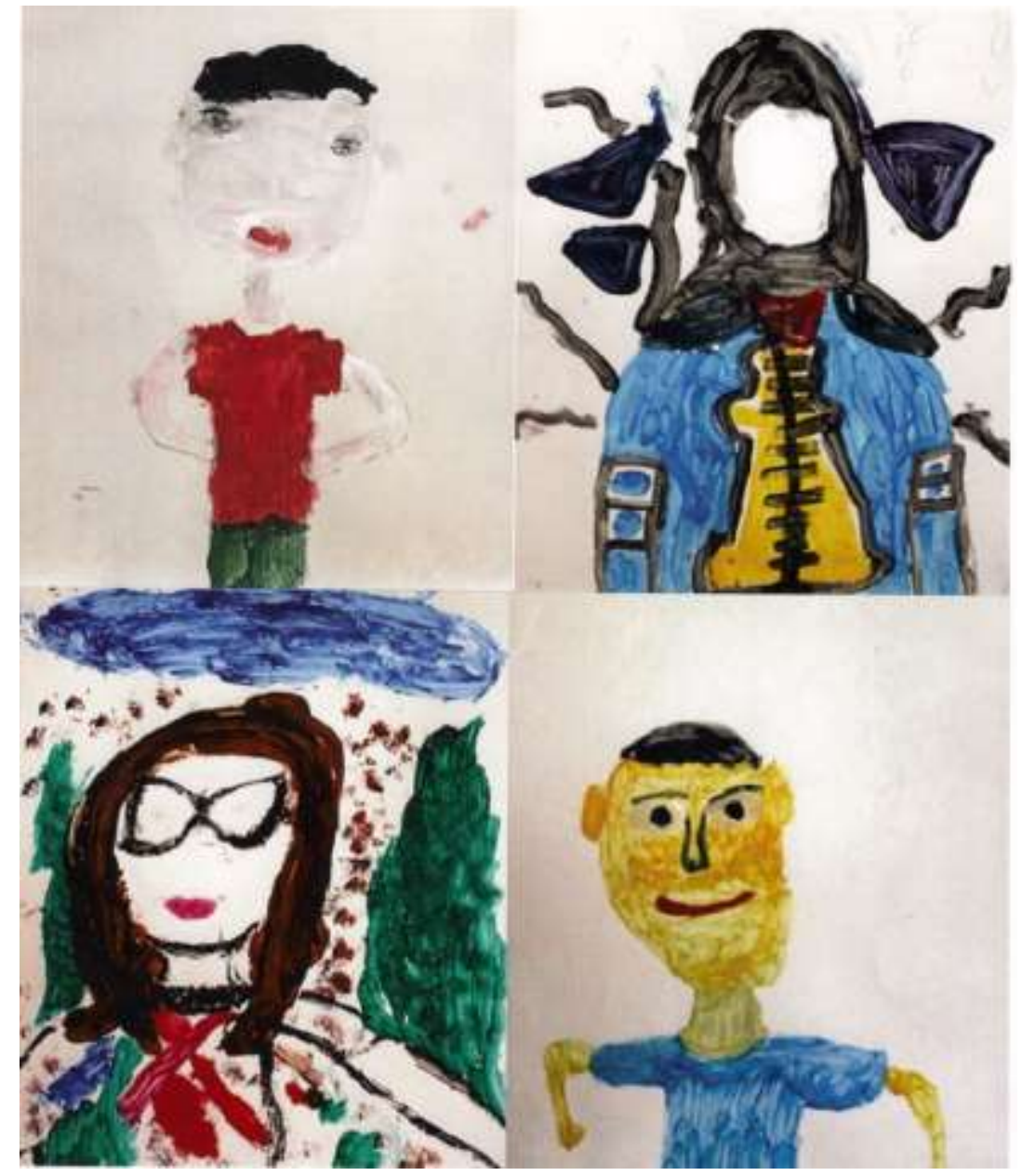

Fonte: autores, 2017.

Olhar de professor, Ponta Grossa, v. 24, p. I-I7, e-I5089.002, 202I.

Disponível em https://revistas2.uepg.br/index.php/olhardeprofessor 
Valdir Heitokoeter de Melo Junior, Marsiel Pacífico e Márcia Barbosa da Silva

Todos os alunos, sem exceção, entenderam a proposta e participaram da atividade, demonstrando não apenas interesse, mas encarando a produção da imagem de si mesmos como um jogo ou desafio a ser superado. Foi possível verificar essas intenções em diversos momentos, quando, por exemplo, os alunos pediam para ver a fotografia mais uma vez, ou, numa alternativa externa, pediam para ir ao banheiro para se olhar no espelho. Tentativas e desafios pueris e criativos que resultaram em autorretratos e alguns breves diálogos sobre cores e formas.

Autorretrato e representação de si é um tema bastante recorrente na história da arte. A título de exemplo, podemos mencionar artistas contemporâneos que se apropriaram do estudo da imagem de si mesmo e da reprodução ou produção dessas imagens para incutir discurso a respeito do tema. $O$ artista Jorge Molder utiliza a fotografia como forma expressiva para tratar da duplicidade. Essa duplicidade parte da ficção de um outro, um personagem que o artista constrói a partir da utilização do seu próprio corpo em autorretratos (SARDO, 2000, p. 10). Outra artista a ser mencionada é Cindy Sherman, fotógrafa norte-americana famosa por seus autorretratos os quais discutem, de diversas formas, os papéis impostos às mulheres - pela sociedade, pela mídia, pela arte (AULER, 2016).

Pode-se citar ainda Amalia Ulman, artista nascida na Argentina, que ganhou destaque internacional ao instaurar uma possivel primeira obra de arte do Instagram. Amalia utilizou a plataforma da rede social Instagram para criar um estereótipo. O primeiro passo foi postar "Part I" (Parte I). Até então, apenas 28 (vinte e oito) dos seus seguidores haviam "gostado". Em seguida, a artista passou a publicar fotografias de si mesma de modo a retratar espaços e costumes que agradassem aos usuários dessa rede social. $O$ índice de seguidores aumentou significativamente a partir do momento em que Amalia passou a publicar imagens com apelo sexual. Ao fim do processo, Amalia havia atingido um público de quase 100.000 (cem mil) seguidores. Resumindo, o objetivo de Amalia era questionar a figura e objetificação do feminino nas mídias.

Da mesma forma, a artista Cindy Sherman, conhecida no meio artístico como "rainha dos autorretratos", juntou-se à comunidade da rede social Instagram em 2017 e, como era de se esperar, passou a usar a plataforma como um meio de se expressar e protestar contra os estereótipos e preconceitos voltados para o machismo e a objetificação do corpo feminino. Esses são apenas alguns exemplos de artistas que se apropriaram do tema autorretrato e propuseram reflexões ligadas a outros temas caros à comunidade e à cultura mundial. Pode-se perceber, portanto, que o autorretrato não é somente uma representação imagética de si, mas uma possibilidade de elaboração de sua autoimagem para si e para o outro.

As sementes do desenvolvimento, da inocência até a experiência, estão presentes nos desenhos de crianças muito pequenas. É necessário compreender que o aprendizado mais importante de arte está

Olhar de professor, Ponta Grossa, v. 24, p. I-19, e-I 5089.002, 202 I.

Disponível em https://revistas2.uepg.br/index.php/olhardeprofessor 
intimamente ligado ao processo da perda da primeira inocência por meio do ganho da experiência temporal (WILSON; WILSON, 20I I, p. 89).

Essa primeira experiência de autorretratar-se e pensar a figura de si mesmo a partir de uma fotografia é, como expresso por Wilson e Wilson, a perda da inocência por meio do ganho da experiência temporal. Os autores afirmam ainda que esse processo pode, de fato, imprimir limitações e ser questionado enquanto processo criativo. No entanto, a influência dos costumes temporais e locais naturalmente se manifesta e determina ações e compreensões. Assim, a atividade contribui para o aprendizado das crianças na medida em que permite a reflexão dos próprios alunos acerca do que vivenciam fora da Escola, em sua relação com a mídia e, consequentemente, facilita o acesso aos meios de emancipação nos mais diversos níveis: cultural, educacional, pessoal, afetivo, entre outros.

Foi possível observar, factualmente, que os alunos enfatizaram as formas e a busca de cores que fosse fiel às fotografias. $O$ fundo branco desprovido da figuração do entorno, evidenciado na maioria dos desenhos, é um exemplo de como os alunos podem ter compreendido o processo. O que importa não é o entorno, mas sim a face, a cor da roupa, algum objeto presente na fotografia que estivesse próximo do corpo do aluno.

Outro aspecto importante a ser ressaltado é a ausência completa de representações estereotipadas, como o clássico desenho de figuração do corpo "palito", evidenciando que a proposta da atividade determina o envolvimento dos alunos e desmistifica falas e costumes comumente encontrados em frases como "não sei desenhar" ou "está feio". O foco e a maneira como a atividade foi apresentada permitiu que os alunos se sentissem à vontade para criar e o resultado das pinturas mostrou que o envolvimento se estendeu para além de um simples desenho ou atividade. Houve observação de cores, tons, formas e a procura por uma representação mais próxima possível do que haviam contemplado nas fotografias.

\section{Considerações finais: olhar para si fora do espelho, o duplo}

Nos primeiros contatos com as crianças da Escola Municipal Professora Juventina Betim da Silva, no que diz respeito à sua relação com a mídia, destacaram-se a proximidade com o celular e o gosto pela produção de selfies. $O$ objetivo era ampliar a experiência com a mídia celular, bem como contribuir para complexificar a relação consigo mesmo por intermédio da autorrepresentação em meios diferentes: a fotografia e o desenho.

Nessa experiência, os alunos tiveram a oportunidade, por meio das conversas iniciais, de conhecer a origem do termo selfie e saber que aquela imagem se referia a eles mesmos: o euzinho. Esse conhecimento se ampliou ainda mais ao entrar em contato com a história dos autorretratos na arte, 
suas especificidades e as experimentações dos artistas. Esse cabedal de informações, aliado à experiência de se autorretratar em fotografia temporizada, em ângulos diferentes dos oferecidos pelo celular, contribui para complexificar e sofisticar a compreensão das diferentes formas de autorrepresentação. Isso pôde ser constatado com a experiência do desenho na qual as crianças entraram em contato com uma outra forma de autorrepresentação a partir de uma auto-observação e memória de si.

Ao aproximar os alunos de reflexões ligadas à autorrepresentação por meio do autorretrato e da selfie, essa temática emerge como um assunto de suma importância para a educação atual, por ser um tema em evidência no círculo cultural artístico, um tema que atinge todas as classes sociais, e por sugerir novos mecanismos e ferramentas de aprendizagem, entre outras coisas.

Além de mostrar o quão atual é este tema, as experiências supramencionadas servem como mediadoras de um diálogo necessário: o diálogo da escola com as mídias e suas interfaces com temáticas que dizem respeito à construção da própria identidade. Podemos dizer que o diálogo está posto, iniciouse. É uma pequena contribuição, muito singela e localizada. Logo, novos estudos, aplicados a diferentes contextos, devem ser realizados e compartilhados. Ainda assim, constitui-se uma contribuição que abre caminho para os alunos questionarem, para não serem abordados de surpresa pelos temas "selfie" e autorretrato, para não ficarem indiferentes aos problemas e aos conhecimentos que tais assuntos podem abarcar.

O trabalho realizado e os resultados alcançados servem de exemplo para experiências semelhantes às quais se pode recorrer na prática docente. Desse modo, é importante reafirmar o compromisso e a relevância da emancipação dos indivíduos e como o uso das mídias, aqui abordado a partir do tema "selfie e autorretrato", pode ser um caminho para pensar as diferentes formas de autorrepresentação, de valorização pessoal, de discussão de estereótipos e também de ressignificação de práticas sociais com mídias que, no limite, levam à objetificação de si.

A postura dos alunos ante a atividade não se restringe apenas a uma prática livresca e espontânea, mas sim remete a uma composição criativa e racional que advém das provocações feitas pelo Grupo LUME. Não se trata, igualmente, de uma condução restritiva de pensamento, que cerceia o pensamento do aluno. As três etapas apresentadas aqui mostram que houve compromisso e interesse em reconhecer, primeiramente, que tipo de experiência os alunos tinham com o tema.

As experiências apresentadas ao longo deste texto reforçam que há alternativas para o uso cotidiano das mídias e, sobretudo, da imagem, como forma de expressão subjetiva das singularidades dos sujeitos. Desde as tensões criadas sobre o cotidiano, na indagação sobre o uso das selfies, até a experimentação de formas de autorretratar-se para além da objetificação da própria imagem, foram propiciadas experiências que ampliaram os sentidos sobre o uso social das imagens a partir de uma perspectiva crítica. Ressalta-se que não se trata de uma receita, muito menos de uma solução para um 
tema tão expansivo e que sofre constantes atualizações, mas sim de uma desmistificação no percurso do ensino para/das mídias. O Euzinho é, antes de qualquer outra denominação, um caminho para conhecermos a nós mesmos e o que nos circunda.

\section{Agradecimentos}

Agradecemos ao programa Universidade Sem Fronteiras e à Escola Municipal Professora Juventina Betim da Silva por propiciarem as condições para a realização do trabalho.

\section{Referências}

AULER, L. C. S. Nítida. 2 I de abril de 2016. Disponível em: https://nitidafotografia.wordpress.com/2016/04/2I/cindy-sherman/. Acesso em I4 set. 2017.

BATEY, M. O significado da marca: como as marcas ganham vida na mente dos consumidores. Rio de Janeiro: Best Business, 2010.

BOGDAN, C. R.; BIKLEN, S.vK. Investigação qualitativa em educação: uma introdução à teoria dos métodos. Porto editora. 1994.

BUENO, S. Dicionário. São Paulo: Didática Paulista. 2000.

COHN, M. C. F. M. Selfie, a cultura do espelho: no espelho. USP, São Paulo - 2015.

DEBORD, G. A sociedade do espetáculo. Tradução Estela dos Santos Abreu. Rio de Janeiro: Contraponto, 1997.

GIL, A. C. Como elaborar projetos de pesquisa. 4. ed. São Paulo: Atlas, 2007.

PACÍFICO, M. O espetáculo de si como tônica da vida no contexto da sociedade excitada. 2017. Tese (Doutorado em Educação) - Universidade Federal de São Carlos, São Carlos, 2017.

PESSOA, H. G. R. Auto-Retrato - o espelho, as coisas. USP, São Paulo - 2006.

SAMPIERI, R.H.; COLLADO, C.F.; LUCIO, M.P.B. Metodologia de pesquisa. 5. ed. Penso. 2013.

SARDO, J. G. F. O tema do autorretrato na obra de Jorde Molder / Lisboa - Escola Superior de Belas Artes - 2000.

SILVA, M. B. O lugar do Estudo das Mídias na Formação de Professores Numa Perspectiva Emancipatória / Natal (RN) - Universidade Federal do Rio Grande do Norte - 20II.

SODRÉ, M. Reinventando a cultura: a comunicação e seus produtos / Muniz Sodré. 5. ed. Petrópolis, RJ: Vozes, 2010. 
SOUSA, L. de. et al. Imagem corporal: Contexto histórico e atual. In: Maria Elisa Caputo Ferreira, Marcela Rodrigues de Castro, Fabiane Frota da Rocha Morgado (Org.). Imagem corporal: reflexões, diretrizes e práticas de pesquisa. Ied. Juiz de Fora: Editora UFJF, 20I4, p.I5-47.

TÜRCKE, C. Sociedade excitada: filosofia da sensação. Tradução Antonio A.S. Zuin, Fabio A. Durão, Francisco F. Fontanella, Mario Frungillo. Campinas, SP: Unicamp, 2010.

WILSON, B.; WILSON. M. Uma Visão Iconoclasta das Fontes de Imagem nos Desenhos de Crianças. In: BARBOSA, A. M. (Org.). Arte-Educação: leitura no subsolo. 8. ed. São Paulo: Cortez, 20I I. p. 5977.

YIN, R. K. Pesquisa qualitativa do início ao fim. Porto Alegre: Penso, 2016.

Recebido em: 04 de abril de 2020.

Versão final recebida em: 26 de setembro de 2020.

Aprovado em: 23 de outubro de 2020.

Publicado online em: 05 de março de 2021 .

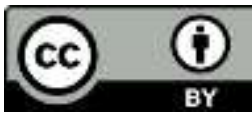

